\title{
A Triticum vulgare Extract Exhibits Regenerating Activity During the Wound Healing Process
}

This article was published in the following Dove Press journal:

Clinical, Cosmetic and Investigational Dermatology

\author{
Annalisa Tito (D) \\ Massimiliano Minale ${ }^{2}$ \\ Salvatore Riccio $\mathbb{1 D}^{2}$ \\ Fabrizia Grieco (iD ${ }^{2}$ \\ Maria Gabriella Colucci ${ }^{1,3}$ \\ Fabio Apone ${ }^{1,3}$
}

'Arterra Bioscience Srl, Naples, 80I42, Italy; ${ }^{2}$ Farmaceutici Damor S.p.A., Naples 80I45, Italy; ${ }^{3}$ VitaLab Srl, Naples, 80I42, Italy
Correspondence: Annalisa Tito

Arterra Bioscience Srl, via Benedetto Brin 69, Naples 80142 , Italy

Tel $+39081658441 \mathrm{I}$

Fax +390812144864

Email annalisa@arterrabio.it
Introduction: Chronic skin lesions represent a problem of increasing occurrence, mostly due to the global ageing of the world population. Research in skin care and dermatology is constantly looking for new non-invasive solutions, preferably those based on the use of natural certified products, able to accelerate the spontaneous skin repair mechanisms and without altering the skin normal appearance and functionality. The wound healing process in the skin is finely regulated by several factors and orchestrated mechanisms, which modulate the progression and the fitting of different consequent phases, including haemostasis, inflammation, cell proliferation and tissue remodelling. It was previously shown that a patented Triticum vulgare aqueous extract was able to trigger the skin repair process by stimulating new tissue growth and reducing the expression levels of inflammatory mediators, such as IL6, TNF $\alpha$, prostaglandin E2, and nitric oxide.

Methods: Scratch assay was performed in Human Dermal Fibroblasts (HDF). The production of fibronectin was measured by gene expression, protein quantification and localization using specific antibodies in HDF. The polymerization of actin was measured using rhodaminphalloidin in HDF. The epidermal lipid content was estimated in HaCaT (human spontaneously immortalized keratinocytes) using Nile Red staining and the increasing GBA gene expression and activity was demonstrated by RT-PCR and enzymatic activity assay.

Results: In the present study, it was demonstrated that the $T$. vulgare extract enhanced cell migration inducing the synthesis of fibronectin, new actin polymerization and stimulating the expression of the Hyaluronan Synthase 2. Furthermore it improved the restoration of the epidermal barrier stimulating lipid synthesis.

Conclusion: In conclusion, we demonstrated that the T. vulgare extract possessed promising potential to be developed as a wound healing promoting agent in skin care and dermatology.

Keywords: plant extract, wound healing, skin cell culture, ECM component, epidermal barrier

\section{Introduction}

Chronic skin lesions due to ageing represent a problem increasingly felt by the National Health Systems which, in both the European countries and in the USA, come to allocate resources up to $2-5 \%$ of the overall healthcare expenditure. ${ }^{1}$ The set of interventions, including the prevention of chronic skin lesions and all those activities of assistance and therapy to promote their healing, is defined as wound care.

Skin wound healing is a complex process, dependent upon the cell types and the chemical mediators interacting in a highly sophisticated time sequence. It is a dynamic process triggered as a response to tissue injury, aims at repairing the matrix and the cell damages, and at restoring the skin barrier integrity, proceeding 
through four overlapping phases: haemostasis, inflammation, proliferation and remodelling. ${ }^{2}$ The healing process starts with the haemostasis stage, consisting of the formation of blood clot that fills up the tissue discontinuity. This stage is connected with the formation of a temporary matrix, the secretion of cytokines and other growth factors that, by interacting with the extra cellular matrix (ECM) components, trigger the whole repairing process. The following inflammatory phase is initiated by neutrophils under the influence of macrophages, which clean the wound area from bacteria and debris and release proinflammatory cytokines and growth factors, in turn, responsible for recruitment and activation of fibroblasts and epithelial cells. ${ }^{3}$ The proliferative phase is characterized by the rebuilding of the damaged tissue, and by an increase in the number of cells in the wound site due to the migration and the proliferation of fibroblasts, endothelial cells and keratinocytes. ${ }^{4}$ During this phase fibroblasts, in the presence of the newly formed blood vessels, proliferate actively and synthesize the ECM components, which, besides their structural role, fulfil a signalling function regulating the dynamic, interactive sequence of biological events. The last phase, the remodelling, occurs when the wound surface is contracted, new epithelium develops and the final scar tissue is formed.

The skin wound healing has been well studied for decades and several plant extracts, and plant-derived products, have been developed with the goal of improving and enhancing the repairing process. ${ }^{5-7}$ Among them, Triticum vulgare has been extensively used in traditional medicine thanks to its properties of accelerating tissue repair. In particular, an aqueous extract of Triticum vulgare, with bioinductive properties, obtained from the whole-germinated plants according to a procedure already described by Sanguigno (2015) and patented (Riccio, 2012), was very helpful in accelerating the wound healing process acting through different mechanisms. ${ }^{8,9}$ It was demonstrated that the extract of Triticum vulgare was able to induce the proliferation of fibroblasts and of endothelial cells giving an acceleration to wound repair. ${ }^{10-13}$ This was confirmed by studies on animal models where it was demonstrated that Triticum vulgare extract regenerated skin lesions. ${ }^{8}$ In particular, the active components of Triticum vulgare extract were isolated and the fraction responsible for the stimulation of tissue regeneration was identified. ${ }^{8}$ This fraction was obtained through ultrafiltration and contains oligosaccharides with an MW higher than 1000 Da. Further evidences indicated that the Triticum extract was also able to reduce the inflammatory reaction and to prevent damages due to the wound-related inflammation. ${ }^{14} \mathrm{Up}$ to this moment, it has been shown that the Triticum extract had pro-healing activity acting on the proliferation phase of wound healing and in chronic inflammation.

The present work was aimed at demonstrating that the patented aqueous extract of Triticum vulgare (TVE), rich in oligosaccharides, exerted a significant wound healing activity regulating also the other important steps of the wound healing process. First of all, we confirmed the effect of TVE in wound healing, already reported in the literature, ${ }^{8}$ then we verified whether TVE was able to increase the synthesis of fibronectin, a key ECM component in the dermis, as well as the expression of Hyaluronan synthase 2 (HAS2), the most abundant HAS in fibroblasts. ${ }^{15}$ Then, we analysed the ability of TVE to enhance actin polymerization in fibroblasts. Actin fibres, the main constituents of the cell cytoskeleton, drive cell motility, adhesion and contraction during the wound healing signalling pathways. ${ }^{16}$ Finally, we studied the effect of TVE on the restoration of the epidermal barrier, by analysing the activity of the enzyme $\beta$ - glucocerebrosidase, main responsible for the production of the ceramides that account for $30-40 \%$ of the stratum corneum lipids.

\section{Materials and Methods Plant Description}

Triticum vulgare, the binomial scientific name of a plant of the Graminaceae family, is the commonly known wheat plant. It is grown under controlled conditions in the Farmaceutici Damor laboratory, Naples, Italy; the voucher specimen is DF/237/2014, and it is deposited in the herbarium of the Medical Botany Chain of University of Salerno, Italy. The commercially available seeds were purchased from the "Consorzio Agrario Lombardo Veneto" (San Giorgio sul Panaro, Modena, Italy).

\section{Triticum vulgare Extract Preparation}

TVE is an aqueous extract of Triticum vulgare, obtained through a patented process (Riccio, 2012): it was prepared according to standard manufacturing protocol of germination under restricted conditions of temperature, light and humidity, extraction using water, sulfuric and chloride acid, and purification with membrane filter as described in Common Technical Document (CTD) and filed at Italian Medicines Agency (AIFA) by Farmaceutici Damor. ${ }^{9}$ The concentrations used for the experiments were $3 \%$ and $15 \%$ 
$(\mathrm{v} / \mathrm{v})$. These concentrations were verified for their safety on the cells performing a MTT assay.

\section{Cell Cultures}

Human Dermal Fibroblasts (HDF, Cell Applications Inc., San Diego, CA) derived from neonatal foreskin and immortalized human keratinocytes HaCaT (AddexBio Technologies, San Diego, CA) were maintained in DMEM supplemented with $10 \%$ of fetal bovine serum in a $95 \%$ air, $5 \% \mathrm{CO}_{2}$ and humidified atmosphere at $37^{\circ} \mathrm{C}$.

\section{Scratch Assay}

$4.5 \times 10^{5}$ cells were seeded in 6 -well plates. $16 \mathrm{hrs}$ later same areas of each well were displaced by scratching a line through the cell layer by a pipet tip. Floating cells were removed by PBS washing. Media containing $0.5 \%$ FBS with or without treatment was added and the cells incubated for $7 \mathrm{hrs}$, TGF $\beta 5 \mathrm{ng} / \mathrm{mL}$ was used as positive control. To estimate the relative migration of the cells, we compared, for each conditions, the unclosed cell-free areas at time 0 and 7 hrs after treatments by using the software Image J.

\section{Gene Expression Analysis}

$1 \times 10^{5} \mathrm{HDF}$ were seeded in 6 well plates, incubated for 16 $\mathrm{h}$ and then treated for $6 \mathrm{hrs}$ with TVE and the positive control for Fibronectin and HAS2 gene expression analyses. To analyse the expression level of $\beta$-glucocerebrosidase (GBA), 1.5 x $10^{5} \mathrm{HaCaT}$ were seeded in 6-well plates and treated for $6 \mathrm{hrs}$ with TVE and the positive control. At the end of the incubation time, total RNA was extracted with the GenElute Mammalian Total RNA Purification Kit (Sigma-Aldrich, Milano, Italy) and treated with DNAse I at $37^{\circ} \mathrm{C}$ for $30^{\prime}$. Reverse transcription was performed using the RevertAid ${ }^{\mathbf{T M}}$ First Strand cDNA Synthesis Kit (Thermo Fisher Scientific, Dallas, TX, USA). RT-PCR was performed with the Quantum RNA ${ }^{\text {TM }}$ kit (Ambion) containing primers to amplify 18S rRNA along with competimers that reduce the amplified 18S rRNA product within the range to be used as endogenous standard. Primers used are listed in Table 1. The amplification reactions were performed using the Mastercycler ${ }^{\mathbf{M M}}$ ProS (Eppendorf, Milano, Italy) with the following general scheme: $2^{\prime}$ at $94^{\circ} \mathrm{C}$ followed by 35 cycles of $94^{\circ} \mathrm{C}$ for $30 \mathrm{~s}, 50^{\circ} \mathrm{C}$ for $30 \mathrm{~s}$, and $72^{\circ} \mathrm{C}$ for $30 \mathrm{~s}$, with a $10 \mathrm{mins}$ final extension at $72^{\circ} \mathrm{C}$. The PCR products were loaded on $1.5 \%$ agarose gel, and the amplification bands were visualized and quantified with the Geliance 200 Imaging system (Perkin Elmer, Woodbridge, Ontario, Canada). The amplification band corresponding to the analysed gene was normalized to the amplification band corresponding to the $18 \mathrm{~S}$ and reported as percentage of untreated controls (fixed as 100\%). RT-PCRs reactions were made in triplicate, and the average results were reported in the graph. The sequence of used primers was reported in Table 1.

\section{ELISA for Fibronectin Protein Measure}

$9 \times 10^{3} \mathrm{HDF}$ were seeded in 96-well plates and treated with TVE and the control for $72 \mathrm{hrs}$. After the treatments, the medium was removed and the cells were washed with PBS $1 x$, fixed in paraformaldehyde (PFA) $4 \%$ for $10^{\prime}$, washed three times with PBS 1x, and permeabilized with 1\% Triton X-100 in PBS for $30^{\prime}$. The cells were then treated for $30^{\prime}$ with $0.5 \%$ Tween 20 and 5\% BSA in PBS and incubated at $4{ }^{\circ} \mathrm{C}$ with primary goat polyclonal antibody, raised against human fibronectin (C-20) (Santa Cruz Biotechnology, Dallas, TX, USA), diluted 1:500 in PBS 1x, containing 0.5\% Tween 20 and 1\% BSA. 16 hrs later, samples were washed 3 times with PBS + $0.5 \%$ Tween 20 , incubated with anti-goat secondary antibody, labelled with Horse-Radish Peroxidase (HRP) (Santa Cruz Biotechnology) and diluted 1:1000 in PBS 1x, containing $0.5 \%$ Tween 20 and 1\% BSA. One hour later, plates were washed 3 times with PBS $1 \mathrm{x}$ and the amount of fibronectin produced by the cells was measured by a colorimetric reaction, using a $0.5 \mathrm{mg} / \mathrm{mL}$ solution of O-PhenylenDiamine (OPD) (Sigma-Aldrich) and $0.012 \% \mathrm{H}_{2} \mathrm{O}_{2}$ in citrate buffer $50 \mathrm{mM}$. The plate was incubated at RT until the yellow colour developed. The absorbance of each sample was measured at $490 \mathrm{~nm}$ by the Multiwell Plate Reader Victor3 (Perkin Elmer).

\section{Immunofluorescence for Fibronectin}

$1.5 \times 10^{5} \mathrm{HDF}$ were seeded on glass slides in 6-well plates and treated with TVE and the control for $72 \mathrm{hrs}$. After the treatments, the medium was removed and the cells were washed with PBS 1x, fixed in paraformaldehyde (PFA) 4\%

Table I List of Primers Used for Gene Expression Experiments

\begin{tabular}{|l|l|l|}
\hline Name of Gene & Forward & Reverse \\
\hline Fibronectin (FN) & CAGGCTCAGCAAATGGTT & AAGTCCCAGCAGCATGATC \\
Hyaluronan Synthase 2 (HAS2) & CTGTGAAAAGGCTAACC & CTAATGCACTGAACACAC \\
$\beta$-glucocerebrosidase (GBA) & AGTTGCACAACTTCAGC & GTCCAGGTACCAATGTAC \\
\hline
\end{tabular}


for $10^{\prime}$, washed three times with PBS 1x, and permeabilized with $1 \%$ Triton $\mathrm{X}-100$ in PBS for $30^{\prime}$. The cells were then treated for $30^{\prime}$ with $0.5 \%$ Tween and $5 \%$ BSA in PBS and incubated overnight at $4{ }^{\circ} \mathrm{C}$ with primary mouse monoclonal antibody, raised against human fibronectin (A-11) (Santa Cruz Biotechnology) diluted 1:200 in PBS 1x, containing $0.5 \%$ Tween and 1\% BSA. After incubation, samples were washed 3 times with PBS $+0.5 \%$ Tween 20, incubated with anti-mouse secondary antibody, labelled with Alexa Fluo 488 (Thermo Scientific) and diluted 1:1000 in PBS 1x, containing $0.5 \%$ Tween 20 and $1 \%$ BSA in presence of DAPI $0.5 \mathrm{ug} / \mathrm{mL}$. One hour later, the slides were washed 3 times with PBS + $0.5 \%$ Tween 20 and the slides were mounted on coverslip using PBS with $50 \%$ of glycerol. The intensity of fluorescence was measured using ImageJ software and the data reported in the graph represented the ratio between the fluorescence intensity and the number of nuclei.

\section{Actin Polymerization Assay}

HDF were seeded at a density of $2 \times 10^{5}$ in 24 well plates, incubated for $16 \mathrm{hrs}$ and then treated with TVE or the control compounds for 30 mins. At the end they were washed with cold PBS 1X, fixed in formaldehyde $4 \%$ for $10^{\prime}$ at $4^{\circ} \mathrm{C}$ and permeabilized with $0.2 \%$ TritonX100 in PBS $1 \mathrm{X}$ for $30 \mathrm{~min}$. The cells were then incubated for $1 \mathrm{hr}$ in the dark with $0.4 \mathrm{mM}$ Rhodamin-Phalloidin in PBS 1X, washed twice in PBS $1 \mathrm{X}$ and solubilized with $300 \mu \mathrm{L}$ of methanol. The plate was read by the Multiwell-plate Reader, Victor 3 (Perkin Elmer), exciting the samples at $530 \mathrm{~nm}$ and recording the fluorescence at $590 \mathrm{~nm}$. Each sample was run in triplicates and the experiments were repeated three times.

\section{GBA Activity Assay}

HaCaT were seeded at a density of $1 \times 10^{5}$ in 6-well plates and treated for $24 \mathrm{hrs}$ with TVE or the positive control. After the treatments, the cells were collected and resuspended in lysis buffer (0.1 M citrate/0.2 M phosphate buffer, $\mathrm{pH} 5.2,0.25 \%$ sodium taurocholate, $0.1 \%$ Triton X-100). The amount of total proteins in each sample was determined by Bradford assay and $25 \mu \mathrm{g}$ of proteins were incubated with $6 \mathrm{mM}$ of the fluorescent GBA substrate, 4-methylumbelliferyl $\beta$ D-glucopyranoside. After $2 \mathrm{~h}$, the reaction was stopped by the addition of $0.1 \mathrm{M}$ glycine/ $0.1 \mathrm{M} \mathrm{NaOH}, \mathrm{pH} 10.7$, and the amount of fluorescent product was measured spectrophotometrically by excitation at $365 \mathrm{~nm}$ and emission at $448 \mathrm{~nm}$, using the Multiwell Plate Reader Victor3 (Perkin Elmer). Each sample was run in triplicate and the average of three independent experiments was reported.

\section{Nile Red Assay}

$1 \times 10^{4} \mathrm{HaCaT}$ were seeded in 96-well plates and grown for $72 \mathrm{hrs}$. Then, the cells were treated with TVE or positive control for 24 hrs. The next day the intracellular lipid content was measured using Nile Red dye (AdipoRed Assay Reagent Lonza): the cells were carefully washed with PBS, and then stained with AdipoRed according to provider instruction. After $10 \mathrm{~min}$, the fluorescence of the samples was measured using an excitation wavelength of $485 \mathrm{~nm}$ and an emission of $570 \mathrm{~nm}$ using Victor3 (PerkinElmer). The intracellular lipid content was related to cell density determined by crystal violet staining.

\section{Statistical Analysis}

Experiments were performed at least three times and the data were expressed as the mean \pm the standard deviation of the values obtained by three independent experiments. Statistical comparisons between controls and treated groups were performed according to $t$-test using the software GraphPad prism version 8. P values lower than 0.05 were considered statistically significant. The number of asterisks in the graphs indicate the level of significance $(* * * \mathrm{p}$ value is between 0.0001 to $0.001 ; * * 0.001$ to $0.01 ; * 0.01$ to 0.05 ).

\section{Results}

\section{Activity of TVE on Wound Repair}

To determine the right usage concentrations, we evaluated TVE cytotoxicity in HaCaT and HDF cells treated for $48 \mathrm{hrs}$ with increasing amount of TVE (from 0.1 to $30 \% \mathrm{v} / \mathrm{v}$ ) and cell viability was determined by MTT assay (data not shown). No significant cytotoxicity was recorded at all concentrations used.

In order to confirm the previous reported data ${ }^{8}$ on the effects of TVE on wound closure acceleration, HDF, grown in monolayer, were mechanically wounded and the closure of wound edges in the presence of $3 \%$ and $15 \%$ of TVE was evaluated by light microscopy. As positive control, due to its ability of wound repair, was used TGF $\beta$ 5ng/mL. ${ }^{17}$ As shown in Figure 1, the two concentrations of TVE accelerated the wound repair capacity of the cells, respectively, by $14 \%$ and $28 \%$.

\section{Activity of TVE on the Synthesis of Dermis ECM Components}

To evaluate whether TVE was capable of modulating new fibronectin synthesis, HDF were treated with TVE at concentrations of $3 \%$ and $15 \%$, and the gene expression and protein 
A

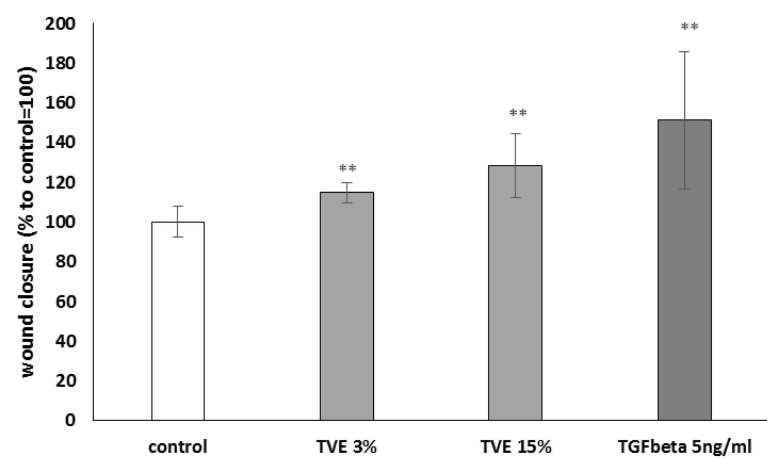

B

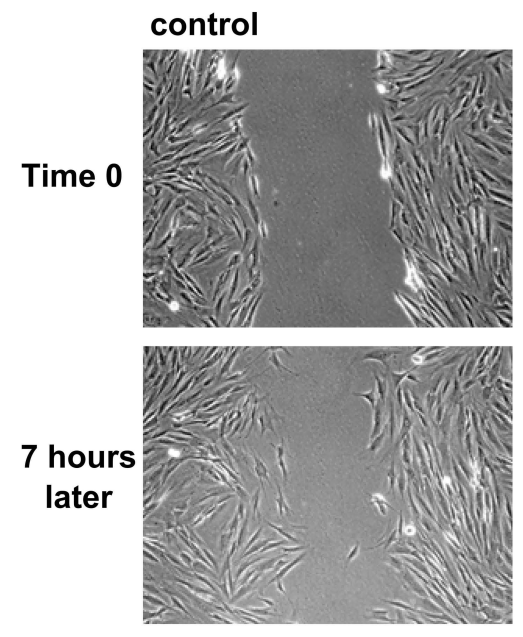

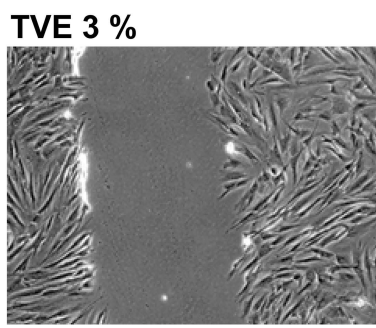

TVE $15 \%$
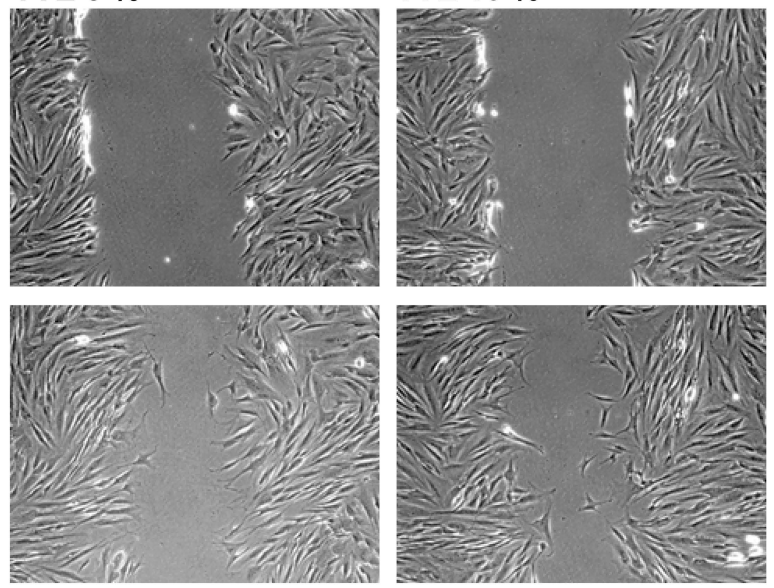

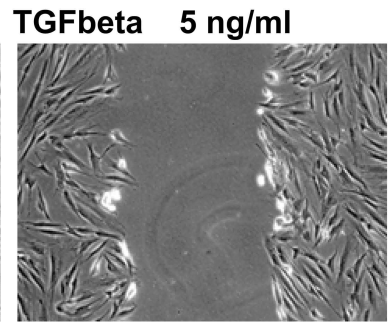

Figure I Effect of TVE on wound closure. HDF were mechanically scratched and then treated with TVE at indicate concentration and analysed after 7 hrs for the wound area measurement. The results, reported in panel $\mathbf{A}$, are the averages of three independent experiments, expressed as percentages respect to the untreated cells, arbitrarily set as $100 \%$. The error bars represent standard deviations and the asterisks indicate statistically significant values (** p value is between 0.001 to 0.01 ). In panel B are reported representative pictures for each treatment.

production of fibronectin were measured by RT-PCR and ELISA assay, respectively. As positive control was used TGF $\beta 5 \mathrm{ng} / \mathrm{mL}$, known for its ability to induce fibronectin synthesis. ${ }^{18}$ As shown in Figure 2, the two TVE concentrations significantly induced both the fibronectin gene expression and production at a similar level. Furthermore, we measured the quantity of fibronectin protein by immuno-fluorescence in way to visualize the protein in the extracellular matrix context. The immunofluorescence results, shown in Figure 3, clearly revealed that TVE, in a dose-dependent way, increased the production of fibronectin. Furthermore, fibronectin was shown to be correctly localized in the extracellular matrix.

In addition to fibronectin, we measured hyaluronan synthase 2 (HAS2) gene expression level after treating HDF with TVE $3 \%$ and $15 \%$. Analogously to the previous experiments, TGF $\beta 2.5 \mathrm{ng} / \mathrm{mL}$ was used as positive control. ${ }^{15}$ TVE at both the concentrations increased the expression of HAS2 by around 70\% (Figure 4).

\section{Activity of TVE on Actin Polymerization in HDF}

To investigate on the activity of TVE on cell migration, we measured the amount of new polymerized actin in HDF after the treatment with $3 \%$ and $15 \%$ of TVE. As controls, $2 \mu \mathrm{g} / \mathrm{mL}$ of phosphatidic acid (PA) and $2 \mu \mathrm{M}$ of cytochalasin $\mathrm{B}$ were used for their effect of increasing and blocking actin polymerization, respectively. ${ }^{19,20}$ TVE treatment, at both concentrations, increased the amount of polymerized actin by almost $250 \%$, indicating a strong stimulatory effect on the formation of the pseudopods, responsible for cell movement and progression (Figure 5).

\section{Effects of TVE on GBA Gene Expression and Activity in Keratinocytes}

To study the activity of TVE on the epidermal barrier formation, the expression and the activity of the enzyme GBA were measured in human keratinocytes (HaCaT), 


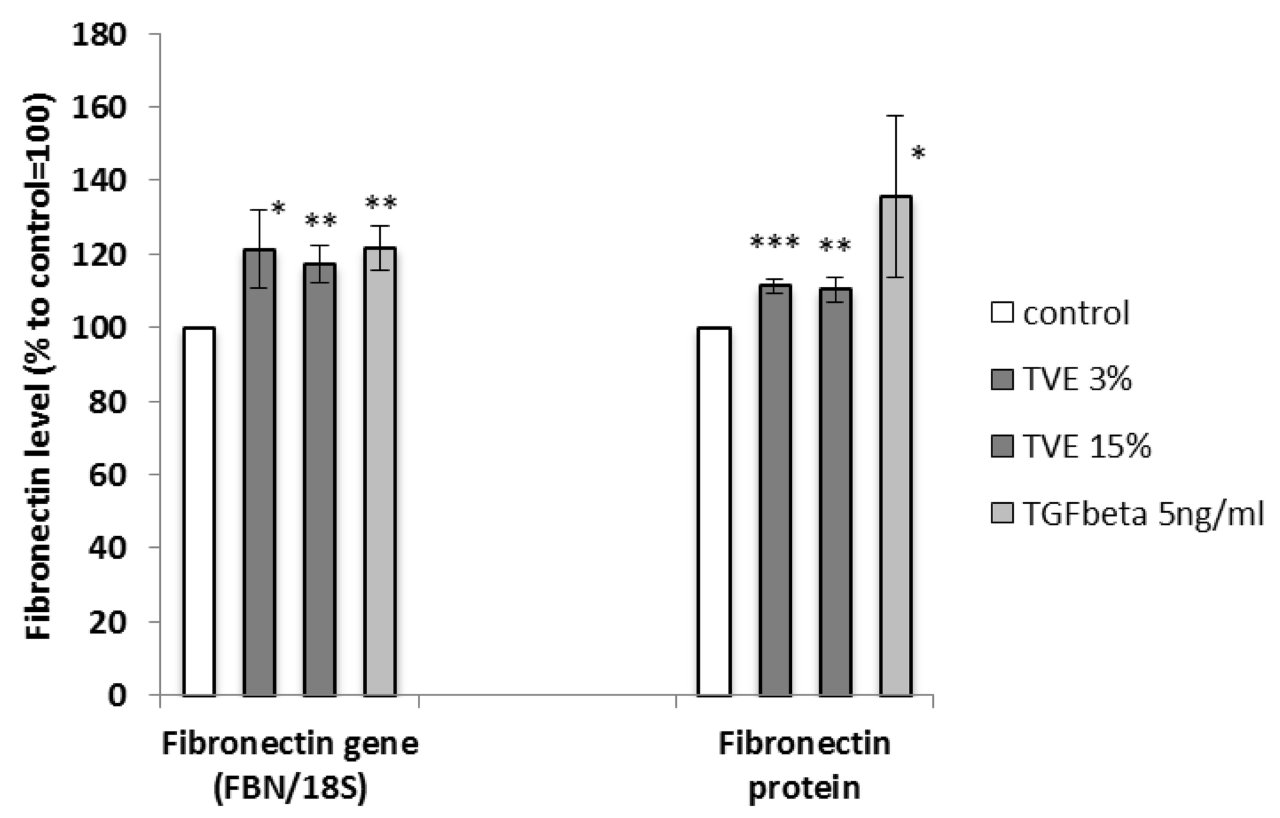

Figure 2 Effect of TVE on fibronectin gene and protein synthesis. HDF were treated with TVE at the indicated concentrations and then gene expression and protein synthesis were analysed after $6 \mathrm{~h}$ and $72 \mathrm{~h}$, respectively. The results are the averages of three independent experiments, expressed as percentages respect to the untreated control, arbitrarily set as $100 \%$. The error bars represent standard deviations, and the asterisks indicate statistically significant values $(* * * *$ value is between $0.000 \mathrm{I}$ to $0.00 \mathrm{I}$; $*^{* *} 0.001$ to $0.01 ; * 0.01$ to 0.05 ).

after the treatment with TVE at $3 \%$ and $15 \%$. As shown in Figure 6A and B, TVE increased both GBA gene expression and protein activity at both the concentrations. The effect on the enzymatic activity was particularly evident, resulting in $136 \%$ and $107 \%$ increases. As positive controls in the assays, Retinoic acid $1 \mathrm{uM}$ and T0901317 $10 \mathrm{uM}$ were used. ${ }^{21,22}$ Furthermore, we analysed if following the increase in expression and activity of GBA, the treatment of TVE induced also an increase in neutral lipid accumulation performing a semi-quantitative fluorescence assay with Nile Red (AdipoRed Lonza). As it is shown in Figure 7 after the treatment with TVE $3 \%$ and $15 \%$ the epidermal lipid content increased by $40 \%$ and $60 \%$, respectively, more than untreated cells. As positive control, T0901317 10uM was used. ${ }^{22}$

\section{Discussion}

In this study, we focused on understanding mechanisms of action of a patented hydrosoluble extract of Triticum vulgare (TVE) on its already identified pro-healing activity in skin cells. We demonstrated that it induced the synthesis of fibronectin and hyaluronan synthase 2, enhanced the polymerization of actin in dermal fibroblasts and stimulated new lipid production in epidermal keratinocytes. These four functions are of key importance for the skin healing process since they are related to the formation of new tissue following the first phase of wound healing. In particular, it was already demonstrated that the Triticum vulgare aqueous extract reduced the expression levels of inflammatory mediators, such as IL-6, TNF $\alpha$, prostaglandin E2, nitric oxide. Then, it was proved that the extract of Triticum was able to increase cell proliferation inducing an acceleration of wound repair. Here we demonstrated that the extract was effective in regulating wound repair also during the remodelling phase. In particular, fibronectin is a key factor during the healing process, as it is involved in cell differentiation and migration, and serves as a binding site for a number of growth factors. ${ }^{23}$ Moreover, it coordinates the deposition of new ECM proteins, such as collagens and thrombospondin I, and promotes cellular adhesion and communication. ${ }^{24,25}$

On the other hand, HAS2 is responsible for the synthesis of HA, which in turn plays an essential role in the formation of new matrix and in the modulation of the wound healing proliferative phase. HA has been extensively linked to tissue hydration, and, as signalling molecule, it interacts with cell surface receptors, stimulating cell migration, proliferation and differentiation. ${ }^{26,27}$ Moreover, it is able to swell and create a woven structure, that enables the coming cells to penetrate the wound area. ${ }^{28}$ By inducing both the factors simultaneously, TVE may favour the formation of the right scaffold factors, required for the migration of fibroblast and for the deposition of new ECM. 


\section{A}

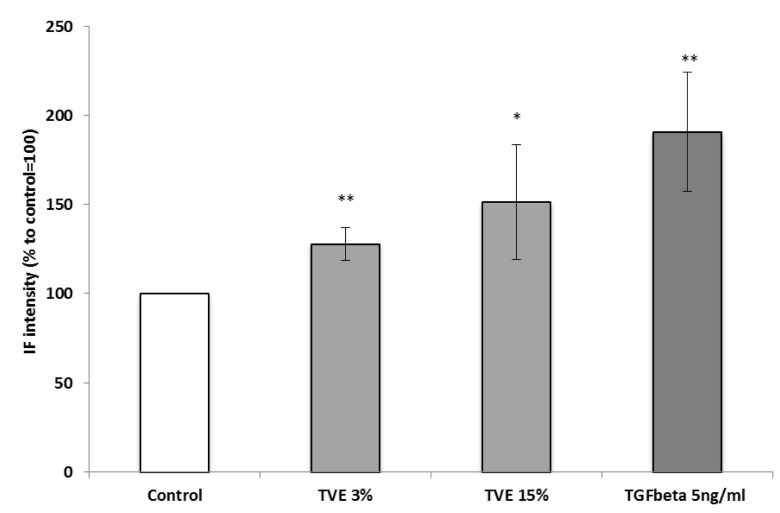

B

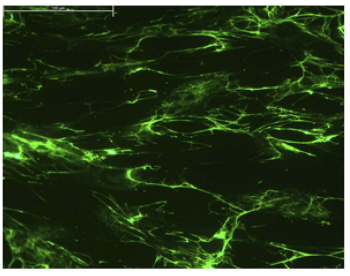

control

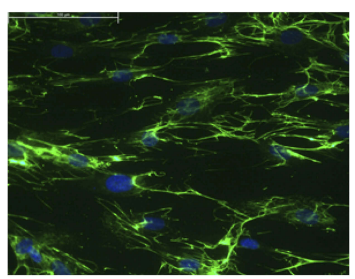

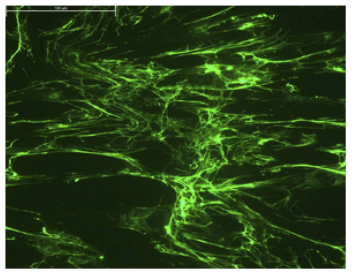

TVE $3 \%$

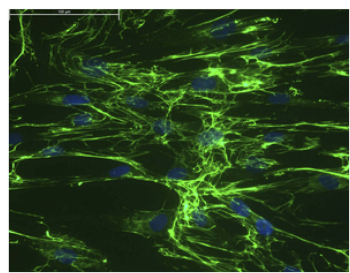

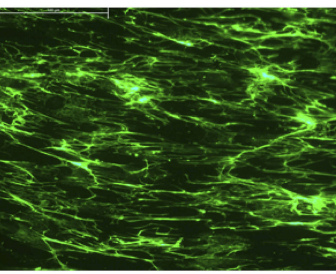

TVE $15 \%$

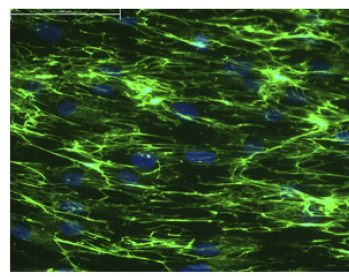

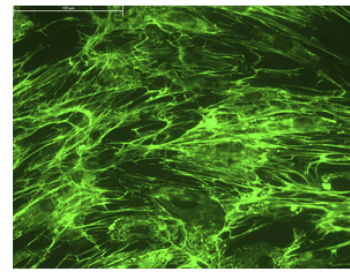

TGFbeta $\quad 5 \mathrm{ng} / \mathrm{ml}$

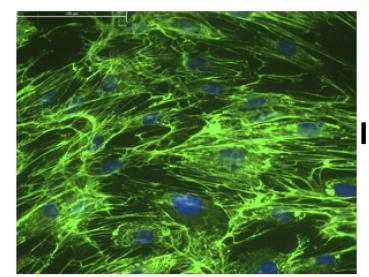

Fibronectin IF

Fibronectin IF/Dapi staining merge

Figure 3 Effect of TVE on Fibronectin protein localization. HDF were treated with TVE at the indicated concentrations and after $72 \mathrm{~h}$ they were processed for immunofluorescence analysis. In the panel A, it was reported the fluorescence quantification corresponding to fibronectin production. The results are the averages of three independent experiments, expressed as percentages respect to the untreated control, arbitrarily set as $100 \%$. The error bars represent standard deviations, and the asterisks indicate statistically significant values $(* * \mathrm{p}$ value is between 0.001 to $0.01 ; * 0.01$ to 0.05$)$. In the panel $\mathbf{B}$, they were reported representative pictures for each treatment.

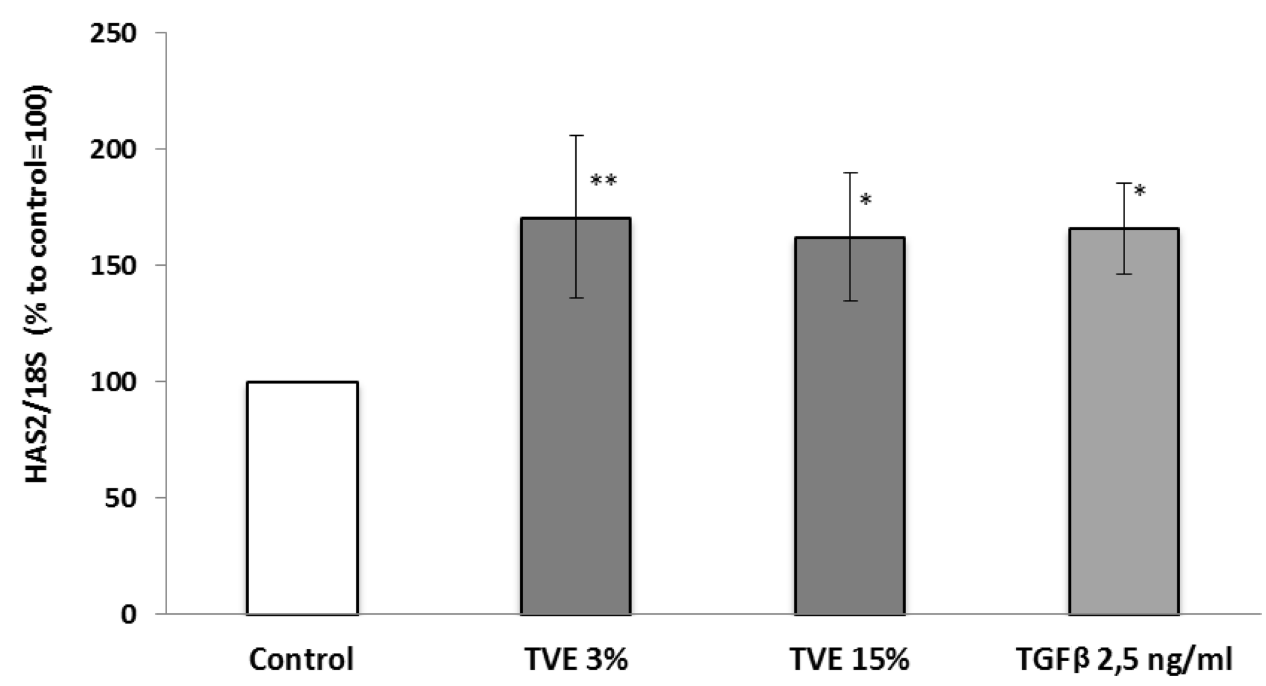

Figure 4 Effect of TVE on hyaluronan synthase 2 gene expression. HDF were treated with TVE 3\% and I5\% for 6 hrs, and then gene expression was analysed. The results are the averages of three independent experiments, expressed as percentages respect to the untreated control, arbitrarily set as $100 \%$. The error bars represent standard deviations, and the asterisks indicate statistically significant values (** $\mathrm{p}$ value is between 0.001 to $0.01 ; * 0.01$ to 0.05 ). 


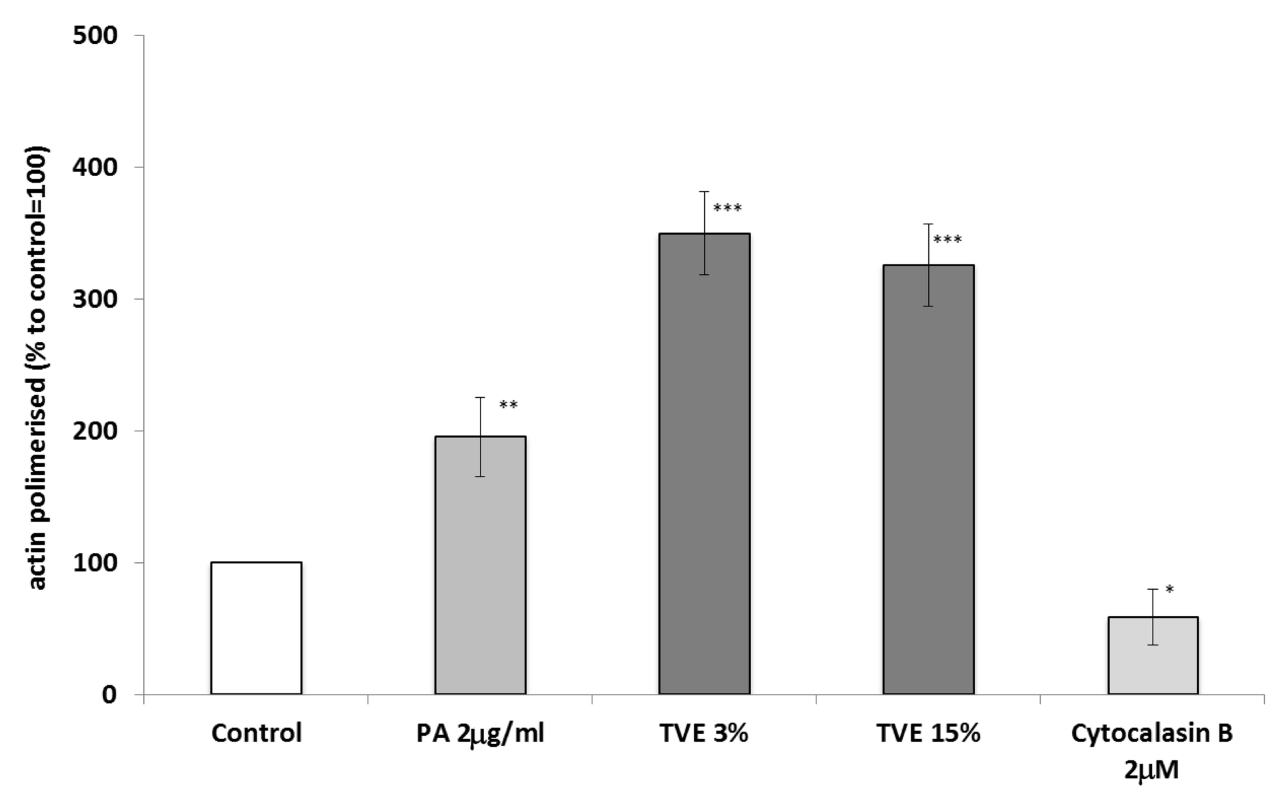

Figure 5 Effect of TVE on polymerization of actin. HDF were treated with TVE at $3 \%$ and $15 \%$ for 30 mins and then polymerized actin was measured in the cell lysates. The results are the averages of three independent experiments, expressed as percentages respect to the untreated control, arbitrarily set as $100 \%$. The error bars represent standard deviations, and the asterisks indicate statistically significant values ( ${ }^{* * *} \mathrm{p}$ value is between $0.000 \mathrm{I}$ to $0.00 \mathrm{I} ; * * 0.00 \mathrm{I}$ to $0.0 \mathrm{I} ; * 0.0 \mathrm{I}$ to 0.05 ).

A

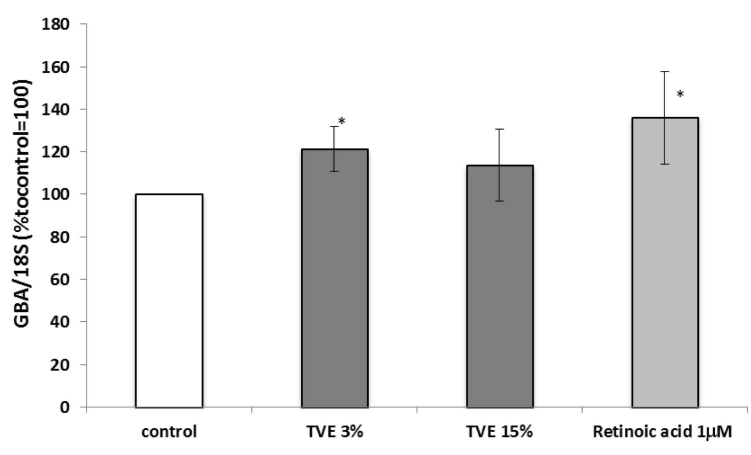

B

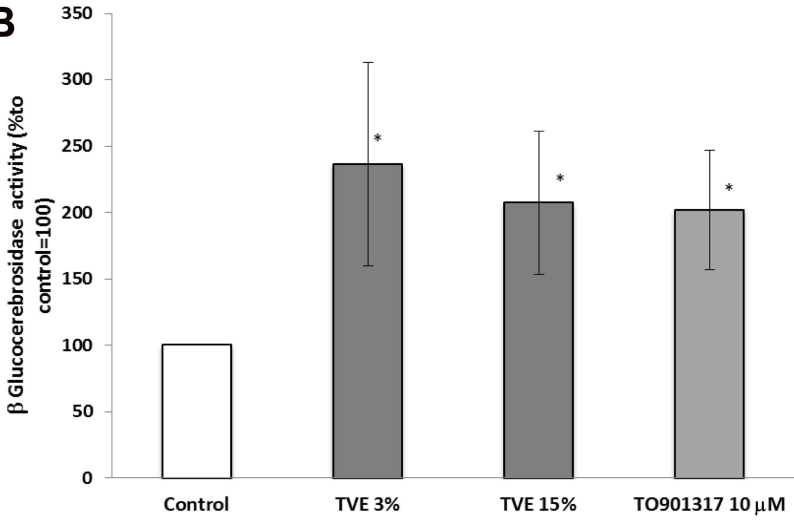

Figure 6 Effect of TVE on GBA gene expression and activity. HaCaT cells were treated with TVE at 3\% and I5\% for 24 hrs, and then both gene expression and enzymatic activity were measured by RT-PCR and GBA activity assay, respectively. In the panel A, it was reported the gene expression analysis, and in the panel B, the enzymatic activity. The results are the averages of three independent experiments, expressed as percentages respect to the untreated control, arbitrarily set as I00\%. The error bars represent standard deviations, and the asterisks indicate statistically significant values ( ${ }^{*} \mathrm{p}$ value is between 0.01 to 0.05 ).

Furthermore, we demonstrated that TVE was able to stimulate the polymerization of actin, the motor of cell contractility and movement. An increase of actin polymerization has been linked to an increase in cell migration on wound edge and an improvement of wound contraction. ${ }^{16}$ By increasing the level of polymerized actin in fibroblasts, TVE could regulate the proliferative and remodelling phases of wound healing, accelerating the ability of fibroblasts to repair the damage. Another key event in wound healing is the skin barrier restoration. In healthy skin, a perturbation of the skin barrier initiates a sequence of events that rapidly results in the return of lipids to the stratum corneum and the restoration of its barrier function. Following a disruption of the barrier, the increase in cholesterol and fatty acid synthesis in the epidermis occurs within few hours, whereas the increase in sphingolipid synthesis requires longer times. ${ }^{29}$ It was demonstrated that the inhibition of the epidermal lipid synthesis delayed barrier function restoration. ${ }^{30}$ By promoting the activity of $\beta$-glucocerebrosidase and the synthesis of new ceramides in keratinocytes, TVE could thus improve the epidermal barrier functions during wound repair. 


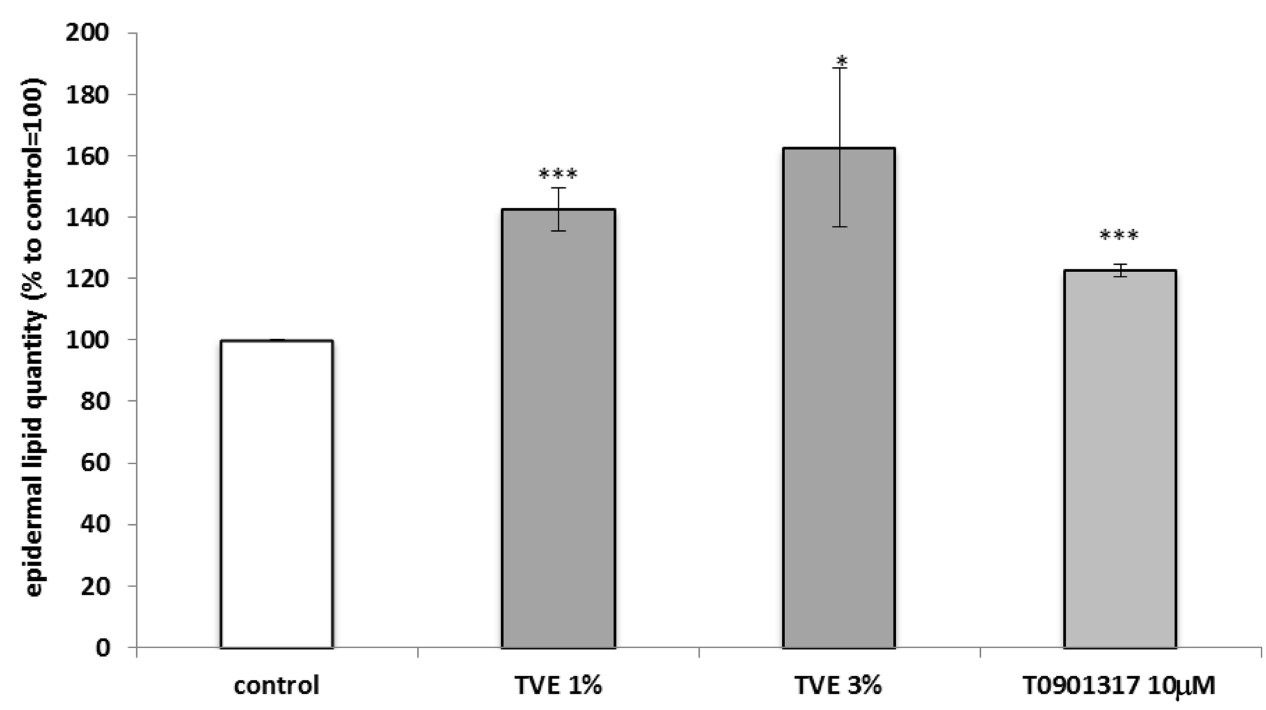

Figure 7 Effect of TVE on epidermal lipid production. HaCaT cells were treated with TVE for 24 hrs and then stained with Nile Red. In the graph, there are reported the average results of three independent experiments, expressed as percentages respect to the untreated control, arbitrarily set as $100 \%$. The error bars represent standard deviations, and the asterisks indicate statistically significant values $\left(* * * \mathrm{p}\right.$ value is between $0.000 \mathrm{I}$ to $0.00 \mathrm{I} ; *^{*} 0.0 \mathrm{I}$ to 0.05$)$.

\section{Conclusion}

In conclusion, this work provides additional clues about the use of a peculiar Triticum vulgare aqueous extract as active ingredient in wound care and dermatology, more specifically addressed to regenerate damaged tissues.

\section{Disclosure}

AT, MGC, and FA are employed by Arterra Bioscience srl; MM, SR, and FG are employed by Farmaceutici Damor S.p.A.; and MGC and FA are employed by VitaLab srl. The authors report no other conflicts of interest in this work.

\section{References}

1. Olsson M, Järbrink K, Divakar U, et al. The humanistic and economic burden of chronic wounds: a systematic review. Wound Repair Regen. 2019. doi:10.1111/wrr.12683

2. Martin P, Nunan R. Cellular and molecular mechanisms of repair in acute and chronic wound healing. $\mathrm{Br} J$ Dermatol. 2015;173 (2):370-378. doi:10.1111/bjd.2015.173.issue-2

3. Lucas T, Waisman A, Ranjan R, et al. Differential roles of macrophages in diverse phases of skin repair. J Immunol. 2010;184 (7):3964-3977. doi:10.4049/jimmunol.0903356

4. Velnar T, Bailey T, Smrkolj V. The wound healing process: an overview of the cellular and molecular mechanisms. J Int Med Res. 2009;37(5):1528-1542. doi:10.1177/147323000903700531

5. Lordani TVA, de Lara CE, Ferreira FBP, et al. Therapeutic effects of medicinal plants on cutaneous wound healing in humans: a systematic review. Mediators Inflamm. 2018. doi:10.1155/2018/7354250

6. Thakur R, Jain N, Pathak R, Sandhu SS. Practices in wound healing studies of plants. Evid Based Complement Alternat Med. 2011;2011:438056. doi:10.1155/2011/438056

7. Lin TK, Zhong L, Santiago JL. Anti-inflammatory and skin barrier repair effects of topical application of some plant oils. Int J Mol Sci. 2018;19:70. doi:10.3390/ijms 19010070
8. Sanguigno L, Minale M, Vannini E, et al. Oligosaccharide fractions derived from triticum vulgare extract accelerate tissutal repairing processes in in vitro and in vivo models of skin lesions. J Ethnopharmacol. 2015;159:198-208. doi:10.1016/j.jep.2014.10.051

9. Riccio R. Saccharide fraction from wheat, isolation process and field of use of the invention. United States Patent 2012 n. 9, 895, 392.

10. Farinella Z, Morale MC, Agosta MR, Rizza V. Stimulation of cell division in mouse fibroblast line $3 \mathrm{~T} 3$ by an extract derived from triticum vulgare. Int J Tissue React. 1986;8(4):337-342.

11. Favit A, Fiore L, Scapagnini U, Canonico PL. An extract derived from triticum vulgare stimulates inositol phospholipid hydrolysis in mouse fibroblasts. Acta Ther. 1992;18(2):171-182.

12. Viano L, Santiano M. Study of the mechanism of action of phytostimulines. G Batteriol Virol Immunol. 1978;71(7-12):176-180.

13. Vanden Berghe DA, Yang QR, Tottè J, Vlietink AJ. Specific stimulation of human endothelial cells by Triticum vulgare extract and its biologically active fraction. Phytother Res. 1993;7:172-178. doi: $10.1002 /$ ptr.2650070216

14. Sanguigno L, Casamassa A, Funel N, et al. Triticum vulgare extract exerts an anti-inflammatory action in two in vitro models of inflammation in microglial cells. PLoS One. 2018;13(6): 0197493. doi:10.1371/journal.pone.0197493

15. Sugiyama Y, Shimada A, Sayo T, Sakai S, Inoue S. Putative hyaluronan synthase mRNA are expressed in mouse skin and TGF- $\beta$ upregulates their expression in cultured human skin cells. J Invest Dermatol. 1998;110(2):116-121. doi:10.1046/j.1523-1747.1998.00093.x

16. Kopecki Z, Cowin AJ. The role of actin remodelling proteins in wound healing and tissue regeneration. In: Alexandrescu VA, editor. Wound Healing - New Insights into Ancient Challenge. IntechOpen; 2016:133-154.

17. Amento EP, Beck LS. TGF-beta and wound healing. Ciba Found Symp. 1991;157:115-123. doi:10.1002/9780470514061.ch8

18. Hocevar BA, Brown TL, Howe PH. TGF-beta induces fibronectin synthesis through a c-Jun N-terminal kinase-dependent, Smad4-independent pathway. EMBOJ. 1999;18(5):1345-1356. doi:10.1093/emboj/18.5.1345

19. Ha KS, Exton JH. Activation of actin polymerization by phosphatidic acid derived from phosphatidylcholine in IIC9 fibroblasts. J Cell Biol. 1993;123(6 Pt2):1789-1796. doi:10.1083/jcb.123.6.1789

20. MacLean-Fletcher S, Pollard TD. Mechanism of action of cytochalasin B on actin. Cell. 1980;20(2):329-341. doi:10.1016/0092-8674(80) 90619-4 
21. Gericke J, Ittensohn J, Mihály J, et al. Regulation of retinoid-mediated signalling involved in skin homeostasis by RAR and RXR agonists/ antagonists in mouse skin. PLoS One. 2013;8(4):e62643. doi:10.1371/ journal.pone.0062643

22. Man MQ, Choi EH, Schmuth M, et al. Basis for improved permeability barrier homeostasis induced by PPAR and LXR activators: liposensors stimulate lipid synthesis, lamellar body secretion, and post-secretory lipid processing. $J$ Invest Dermatol. 2006;126 (2):386-392. doi:10.1038/sj.jid.5700046

23. Pankov R, Yamada KM. Fibronectin at a glance. J Cell Sci. 2002;115 (Pt20):3861-3863. doi:10.1242/jcs.00059

24. Sottile J, Hocking DC. Fibronectin polymerization regulates the composition and stability of extracellular matrix fibrils and cell-matrix adhesions. Mol Biol Cell. 2012;13(10):3546-3559. doi:10.1091/mbc.e02-01-0048

25. Lenselink EA. Role of fibronectin in normal wound healing. Int Wound J. 2015;12(3):313-316. doi:10.1111/iwj.12109
26. Necas J, Bartosikova L, Brauner P, Kolar J. Hyaluronic acid (hyaluronan): a review. Vet Med (Praha). 2008;8:397-411. doi:10.17221/1930VETMED

27. Litwiniuk M, Krejner A, Grzela T, Gauto AR, Grzela T. Hyaluronic acid in inflammation and tissue regeneration. Wounds. 2016;28(3):78-88.

28. Koźma EM, Olczyk K, Glowacki A, Korbut R. Wound repair. $A d v$ Hyg Exp Med. 1998;52:173-185.

29. Qiang MQ, Elias PM, Feingold KR. Fatty acids are required for epidermal permeability barrier function. J Clin Invest. 1993;92 (2):791-798. doi:10.1172/JCI116652

30. Holleran WM, Man MQ, Gao WN, Menon GK, Elias PM, Feingold KR. Sphingolipids are required for mammalian epidermal barrier function. Inhibition of sphingolipid synthesis delays barrier recovery after acute perturbation. $J$ Clin Invest. 1991;88 (4):1338-1345. doi:10.1172/JCI115439

\section{Publish your work in this journal}

Clinical, Cosmetic and Investigational Dermatology is an international, peer-reviewed, open access, online journal that focuses on the latest clinical and experimental research in all aspects of skin disease and cosmetic interventions. This journal is indexed on CAS.
The manuscript management system is completely online and includes a very quick and fair peer-review system, which is all easy to use. Visit http://www.dovepress.com/testimonials.php to read real quotes from published authors. 